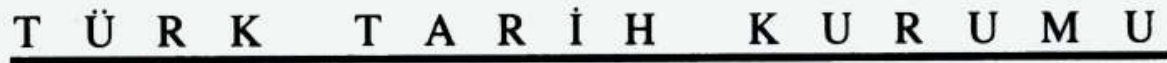 \\ BELLETEN

\section{KÜLTEPE METINLERINDE GEÇEN amūtu(m) ÜZERINE}

\section{SEDAT ERKUT*}

1983 yılında Doktor unvanı aldığımız tezin konusu Çivi Yazılı Boğazköy Tabletlerine Göre Hititler Devrinde Demir idi. Bu çalışmayı yaparken Hitit öncesi dönem de doğal olarak ilgi alanımıza giriyordu.

Asur Ticaret Kolonileri çağında amūtu(m) ve onun sinonimi kabul edilen -muhtemelen bir işlemden sonra elde edilen- aši'u(m)'un demir ya da onun türevleri olabileceği görüşü kimi bilim adamlarınca benimsenmişti. Örneğin; K.Balkan, soru işaretiyle bile olsa "Kültepe'de ele geçen demir cürufuna amūtu'dan artakalan" olarak söz etmekteydi' ${ }^{1}$.

Hocam E.Bilgiç bu konuya çok daha önce açıklık getirmişti. Söz konusu maddelerin demir olamayacağını Goetze'ye dayanarak kesin olarak belirtmiştir". "Madem parzillu Akadca'da demir için var olan sözcüktür, o halde bu konuda yeni sözcük bulmaya çalışmak anlamsızdır." diyor. Ayrıca aynı makalesinde altundan daha değerli bir metal olan platin'in teknik nedenlerden ötürü o devirde üretilemeyeceğini savunmaktadır.

Doktora çalışmamız sırasında amūtu'nun demir olmadığı konusu bizce kesinleşmişti. Doktora çalışmalarımız zamanından beri amūtu ve aši'u'un günümüzdeki karşlıklarının ne olacağı zihnimizi hep meşgul etti. Biz bu

* A.Ü. Dil ve Tarih-Coğrafya Fakültesi Öğretim Üyesi.

1 K.Balkan, Kaniş Karumu'nun Kronolojisi, (1955) s.21.

2 E.Bilgiç, "Asurca Vesikalara Göre Etilerden Önce Anadolu'da Maden Ekonomisi", Sumeroloji Araşurmaları, 1940-1941, Dil ve Tarih-Coğrafya Fakültesi Yillık Çalışmaları Dergisi'nin 1. sayısından ayrıbasım, 1941 , s.58 vd.; biz burada E. Bilgiç'ten önce yapılan çalışmaları altnot olarak vermedik. İsteyen araşturmacı E. Bilgiç'in sōz konusu makalesinden onun verdiği kaynaklara ulașabilir. 
maddenin metal olamayacağını değerli bir taş olabileceğini düşünüyorduk. C.Günbattu ile yaptığımız bir söyleşide ikimiz de amūtu'nun metal olmayacağını değerli bir taş olabileceği görüşünde birleştik. Biz de böyle düşündüğümüz için tetiklendik. Biriktirdiğimiz yayımlanmış Kültepe malzemesi üzerine odaklandık. Meslektaşımız C.Günbatu ve Asiriyolog meslektaşlarımız da malzeme ve fikir bakımından yardımcı oldular ve bu çalışma ortaya çıkt.

E.Bilgiç diyor ki: "amūtu Kapadokya vesikalarında altından beş misli daha pahalıdır. Rimuş'un Sumerce-Akadca kitabesinde Sumerce AN.NA (kalay) Akadça paralelinde amūtu'nun Sumerogramı olan KÙ.AN geçmekte ve bundan bir statü yapıldığı bildirilmektedir. Amarna çağı mektuplarında amūtu'dan yapılmış bir șişenin (lahannum) Mitanni kralı Tuşratta'dan Mısır kralı III. Amonofis'e hediye edildiği anlaşılıyor".

E.Bilgiç'in bildirdiğine göre Kültepe metinlerinde parça parça toplanıp, altundan beş misli değerli olan bu madde eritiliyordu. Eritme işleminde ağırlığından kaybetmekteydi (cüruf). E.Bilgiç'in ifadesi aynen şöyledir: 1 mana amūtu eritildikten sonra $2 / 3$ šiklum miktarında, daha küçük kıymette amūtu kišrum = Amutu cürufu?. Daha anlaşılır biçimde şöyle ifade edilebilir: Anadolu içlerinden toplanmakta, eritirken ve anlaşılamayan diğer bir ameliye (i-na ši-ra-tim) esnasında ise 4 šiklum daha eksilmektedir.

İlgili metin CAD Ș s.102 (1962)'de şöyle deniliyor: Șarāpu: to refine (metals by firing) : (1 mana) amūtam is-ru-up-šíma $2 / 3$ GíN kisrum èliam lu ina ša-ra-pí-im lu ina ší-ra-tim mutae 4 GÍN e-ta-x-a: (İngilizcesi) He refined the amūtu-metal and a lump (weighing) two-thirds of a shekel came out (of the kiln, either through the refining or through the... (there occured) a loss of four shekels .: (Türkçesi) O amūtum'u rafine etti ve firından bir šeqel'in `2/3'ü parça yumru çıktı, ya rafine edilmesinden dolayı ya da... ...(Orada) 4 šeqel azaldı (kaypp oldu) (CCT 4 4a:38 ve 41) (širatim 41. saturda geçiyor).

(Bilgi için ağırlıklar: 2/3 šiklum $\pm 6-7$ gr., 4 šiqlum 30 gr.'dır.)

E.Bilgiç amūtu'nun Hatti'den satın alındığını ve ticaretinin gizli olarak yapıldığını bildiriyor.

Öte yandan amūtu'nun alım satımının Kuššara sarayının tekelinde olduğunu bildiriyor. E.Bilgiç'in makalesinden anlaşıldığına göre kalay ile 
amūtu arasında sıkı bir ticari ilişki söz konusudur. Son olarak amūtu'dan yüzük yapıldığı bildirilmektedir ${ }^{3}$.

H.Sever'in yukarıdaki bilgiler dışında aşağıda adresini verdiğimiz bildirisinde ki bizim için önemli saptamaları şöyle: amūtu gümüşten 90 misli değerlidir.

Bir metin yerinde "demirci ile, ufalanmış amūtu için ikişer buçuk šeqel mamul altun karşılı̆̆ı anlaştuğını" belirtiyor.

Öte yandan amūtu'dan yapılmış gerdanlık söz konusudur ${ }^{4}$.

S.Çeçen amūtu üzerine kapsamlı çalışmasını sunduğu makalesinde KÙ.AN'ın amūtu ile aynı olduğunu pekiştiriyor. Ayrıca amūtu'dan yapılan objeleri belgeleyerek şu biçimde sergiliyor: Çeçen'in makalesinin ilgili kısmında "Bu madenden yüzük süslemelerinde ve kadın ziynet eşyalarından olan iğneliklerin baş kısmında kullanıldığı biliniyordu. Elimde bulunan yeni bir vesikada bu madenin yüzükte kullanılırken halka şeklinde altun sarılarak zenginleştirildiği görülmektedir. Bunları destekleyen yeni metin yerlerine de sahibim. Bu eşyalar dışında amūtu'nun taç olarak da kullanıldıkları ilk defa görülmektedir. ${ }^{55}$ diyor.

Diğer yandan C.Günbattı Koloni Çăğ'nın önemli bir belgesi olan Kt.n/k 504 no'lu tabletten önemli bir noktayı belirtmiştir. Söz konusu belgede 'Kral ve Kraliçe tutuklunun salıverilmesi için, düşmanları Tawiniya kralı ile ilişkisi olan ve kendileri aleyhine bazı faaliyetlerde bulunduğundan söz ettikleri diğer bir şahsın teslim edilmesini; bu yapılmaz ise, kendilerine 1 mina amūtu veya 10 mina altın verilmesini istemişlerdir. Nihayet, bu şartların yerine getirilmemesi ve Tawiniya kralına hizmet etmekle itham edilen kimsenin adının açıklanmaması durumunda, Assur-taklaku'nun öldürüleceğini bildirmişlerdir. ${ }^{36}$

${ }^{3}$ H. Sever, “Asur Ticaret Kolonileri Çağı'nda (M.Ö.1970-1750) Anadolu Dışına Çıkışı Yasaklanan Bazı Madenler", XII. Tarih Kongresi, Kongreye Sunulan Bildiriler, Ankara, 12-16 Eylül 1994, T.T.K. Yayın, 1999, s.92 vd.

${ }^{4}$ H. Sever, "Asur Ticaret Kolonileri Çağı'nda (M.Ỏ.1970-1750) Anadolu Dışına Çıkışı Yasaklanan Bazı Madenler", XII. Tarih Kongresi, Kongreye Sunulan Bildiriler, Ankara, 12-16 Eylül 1994, T.T.K. Yayın, 1999, s.92 vd.

${ }^{5}$ S.Çeçen, "Kaniš Karumu'nun Diğer Karum ve Wabartumlar'a "KÙ.AN" (amutum) ile İlgili Önemli Talimatlan", Belleten, Say1 231, 1997, s.220 vd.

${ }^{6}$ C. Günbatt, "Eski Anadolu'da 'Su Ordali'", Archivum Anatolicum, Vol 4, Ankara Üniversitesi, Dil ve Tarih- Coğrafya Fakültesi, Ankara, 2000, s.77-88. 
Buradan en azından 1 mina amūtu'nun 10 mina altın ile eş değer olabileceği düşünebilir.

Meslektaşım Şerife Yılmaz amūtum ile ilgili yaptığı çok kapsamlı çalışmada üç adet tablet işlemiştir. İlk iki tablet amūtum ile ilgili pek bir şey kazandırmamaktadır. 3. tablet Kt.j/k 623(161-611-64)'dir. Bu tablet önemli olabilir. Ancak bazı okuma zorluklarından dolayı bir sonuç çıkmamaktadır ${ }^{7}$. Bu tablet yeniden ele alınmalıdır; değerli meslektaşım bu belgeden muhakkak güzel sonuçlar çıkaracaktır.

Son olarak İ. Albayrak'ın amūtum için bana yan çıkan önemli bir ifadesi var 'kıymetli bir maden veya taş' demektedir"8.

S.Ö.Savaş'ın kitabının 42. sayfasında "2) Hitit Devri Yazılı Belgelerinde Madenler ve İşlevleri" baş̧ı̆̆ının alt başlığında "a) Başlıca madenlerin 3 dildeki karşılıkları" yer almakta bu çizelgede şöyle bir eşitlik söz konusudur: AN.BAR $\mathrm{GE}_{6} / \mathrm{KU}$.AN (Sumerce) $A M \bar{U} T U=A \breve{S} I^{\prime} U$ (Akadça) meteor demiri/platin (Anlam) olarak verilmekte. Buradan sanki Hitit metinlerinde $A M \bar{U} T U$ ve $A S I^{\prime} U$ geçiyor izlenimi uyanmakta. Bilindiği gibi Hitit çiviyazılı belgelerinde hiçbir zaman söz konusu Akadça sözcükler geçmemektedir'.

Coğunlukla Koloni çağı belgelerinde geçen Akadça amūtu $(m)$ 'un Hitit metinlerinde geçen Sumerce olası karşılığı bizce (NA ${ }_{4}$ DUH.ŠU.A (Quarz?, Bergkristall?, Diorit?)'dir ${ }^{10}$. Bu maddenin Hititçesi olasılıkla parashi/a-' $\operatorname{dir}^{11}$.

Sonuç olarak söz konusu maddenin günümüzde orta derecede değerli taş olan, 6-6,5 sertliğinde ve 600 santigrat derecede eritilip şekillendirilebilen, kalıba dökülebilen ülkemizde bolca bulunan AMETEIS (kuvars, kaya kristali, dă̆ kristali) ile söz konusu amūtu(m)'un aynı madde olduğunu öne sürüyoruz.

Yukarıda adını belirttiğimiz bu Sumerce ve Hititçe iki sözcüğün çivi yazılı Hititçe belgelerdeki durumunu ve arkeolojik görsel belgeleri en kısa zamanda yayımlayacağız.

${ }^{7}$ Ș.Yılmaz, "KÙ.AN (amutum) Maden İle İlgili 3 Yeni Belge", Anadolu Medeniyetleri Müzesi 1999 Yillı̆̆ı, s.158-163.

${ }^{8}$ I.Albayrak, Kültepe Tabletleri IV, T.T.K. Yayın, 2006, s.166

${ }^{9}$ S.Ö.Savaş, Çivi Yazılı Belgeler Işığında Anadolu'da (İ.Ö. 2. Bin Yilında) Madencilik ve Maden Kullanumi, T.T.K.Yayın, 2006, s.42 vd.

${ }^{10}$ C.Rüster,E.Neu, Hethitisches Zeichenlexikon, StBoT Beiheft 2, 1989, no.164.

${ }^{11}$ A.M.Darga, Hitit Sanat, Akbank Kültür ve Sanat Kitapları, 56, 1992, s.111. 